\title{
Synthesis and characterization of functionalized CNTs using soya and milk protein
}

\author{
Sanjay saxena $\cdot$ Rachana ranu $\cdot$ Chandan Hait • \\ Shruti Priya
}

Received: 12 June 2013 / Accepted: 23 July 2013/Published online: 20 August 2013

(C) The Author(s) 2013. This article is published with open access at Springerlink.com

\begin{abstract}
Nanotechnology is the study of the phenomenon and manipulation of matter at atomic and molecular scale to enhance their older property and generate several new properties. Carbon nanotubes (CNTs) are one of the most commonly mentioned building blocks of nanotechnology. CNTs are very prevalent in today's world of medical research and are being highly researched in the fields of efficient drug delivery and bio sensing methods for disease treatment and health monitoring. There are number of methods for synthesizing CNTs. This is a biological method for synthesis of CNTs in which protein is used as carbon source and amino acids present in protein form complex with metal salt. The CNTs synthesized are then characterized and functionalized using techniques such as transmission electron microscopy, Fourier transform infrared, nuclear magnetic resonance, ultra-violet visible spectroscopy, X-ray diffraction, etc. The properties of the synthesized CNTs are studied with the help of techniques such as thermo-gravimetric analysis, differential thermal analysis, and vibrating sample magnetometer, etc.
\end{abstract}

Keywords Amino acids · TEM · VSM · FTIR · IR · UV · TGA $\cdot$ DTA $\cdot$ XRD $\cdot$ Chemical structure

S. saxena

Department of Chemistry, NIMS University, Jaipur, India

R. ranu

Department of Nanotechnology, NIMS University, Jaipur, India

C. Hait $(\square) \cdot$ S. Priya

Department of Biotechnology, NIMS University, Jaipur, India

e-mail: chandanhait.biotech@gmail.com

\section{Introduction}

Carbon nanotubes (CNTs) are allotropes of carbon. These cylindrical carbon molecules have novel properties that make them potentially useful in many applications in nanotechnology, electronics, optics and other fields of materials science, as well as potential uses in architectural fields. They exhibit extraordinary strength and unique electrical properties, and are efficient conductors of heat (Dresslhaw et al. 2008). Due to their exceptional properties a new method is developed using amino acid. The CNTs formed are already functionalized and can be used directly in various applications like targeted drug delivery. In targeted drug delivery, CNTs need to be functionalized so that drug should be attached with it (Bianco et al. 2005; Elhissi et al. 2012).

\section{Experimental details}

In the preparation of CNTs by chemical method the concentration of carbon at a particular point should be high. Without satisfying this condition CNTs cannot be prepared by this method. So protein is taken as carbon source and cobalt salts are taken as catalyst. The choice of protein is because of the presence of two connecting sites $\left(-\mathrm{NH}_{2}\right.$ and $\left.-\mathrm{COOH}\right)$ within one single molecule. Due to the presence of two connecting sites and $\mathrm{Co}^{2+}$, present in cobalt salt different protein chains are clubbed together and hence concentration of carbon at a point is increased (Tiwari et al. 2011). The major source of protein is Amway protein which is a mixture of soya and milk protein. This protein powder is manufactured by Nutrilite, USA which is a renowned dietary supplement company. As per the claims of the company $100 \mathrm{~g}$ of Amway protein contain $85 \mathrm{~g}$ of protein and 17 amino acids.

Synthesis of CNTs using Protein and metal salt is a twostep process. In first step a complex of protein and metal 
salt is prepared and dried. In second step the dried material is decomposed in the muffle furnace to obtain CNTs. For the preparation of CNTs using Amway protein (blend of soya and milk protein) in aqueous solution, first $1 \mathrm{~N}$ solution of $\mathrm{CoCl}_{2}$ is prepared in water and $20 \mathrm{ml}$ of it is mixed with $20 \mathrm{~g}$ of protein blend for the reaction. The reaction mixture is kept undisturbed for $24 \mathrm{~h}$ for self-precipitation of complex. After $24 \mathrm{~h}$ jelly like pink complex is formed. The complex is then kept in desiccators for around 7 days. After 7 days the complex is washed with water and dried again. The weight of dry complex is $30.65 \mathrm{~g}$. The complex is now ready to decompose and for further studies.

The complex formed is decomposed at $850{ }^{\circ} \mathrm{C}$ in a muffle furnace. For decomposition $25 \mathrm{~g}$ of complex is weighed and kept in crucible. The complex is then kept in muffle furnace for $10 \mathrm{~min}$ at $850{ }^{\circ} \mathrm{C}$. The weight of decomposed complex is $4.489 \mathrm{~g}$.

\section{Purification of CNTs formed}

Purification is also a two-step process.

Step 1: In first step the CNTs are heated in the furnace to remove volatile contents. At the time of decomposition significant weight loss of around $80 \%$ material is observed.

Step 2: In second step the metal content is removed. For removal of metal contents $4.489 \mathrm{~g}$ of the CNTs were mixed with $\mathrm{HCl} .6 \mathrm{ml}$ of $12 \mathrm{M} \mathrm{HCl}$ is taken per grams of CNTs. The mixture is kept as such for $24 \mathrm{~h}$. After $24 \mathrm{~h}$ the material was centrifuged and washed with water for several times. The purified CNTs were then filtered and dried. The dry weight of purified CNTs was $3.667 \mathrm{~g}$.

\section{Results and discussion}

Characterization is carried out in two steps:

Step I: characterization of amino acid metal complex

The chemical compound prepared by reaction of protein and metal salt is characterized using NMR and IR.

\section{$N M R$}

The NMR spectra of compound prepared by the reaction of Cobalt salt and Amway protein in aqueous medium are shown in Fig. 1 and Table 1.

\section{$U V$-visible spectroscopy result}

The UV spectra of compound prepared by the reaction of Cobalt salt and Amway protein in aqueous solution are shown in Fig. 2 and Table 2.
IR spectroscopy result

The IR spectra of compound prepared by the reaction of Cobalt salt and Amway protein in aqueous solution are shown in Fig. 3.

The IR spectrum describes the presence of different functional groups at various absorption bands which is illustrated in the following Table 3.

On the basis of NMR, UV and IR results the following structure of amino acid is deduced.

\section{Chemical interpretation}

The above results show the presence of following groups in the chemical compound. The structure deduced by the following results was containing $\mathrm{NH}^{3+}$, $\mathrm{COOH}^{-}$, aliphatic amines. The structure deduced was $\mathrm{C}_{9} \mathrm{H}_{18} \mathrm{~N}_{2} \mathrm{O}_{4}$. It is very closely related structure to the amino acid-LYSINE.

Formula: $\mathrm{C}_{6} \mathrm{H}_{14} \mathrm{~N}_{2} \mathrm{O}_{2}$

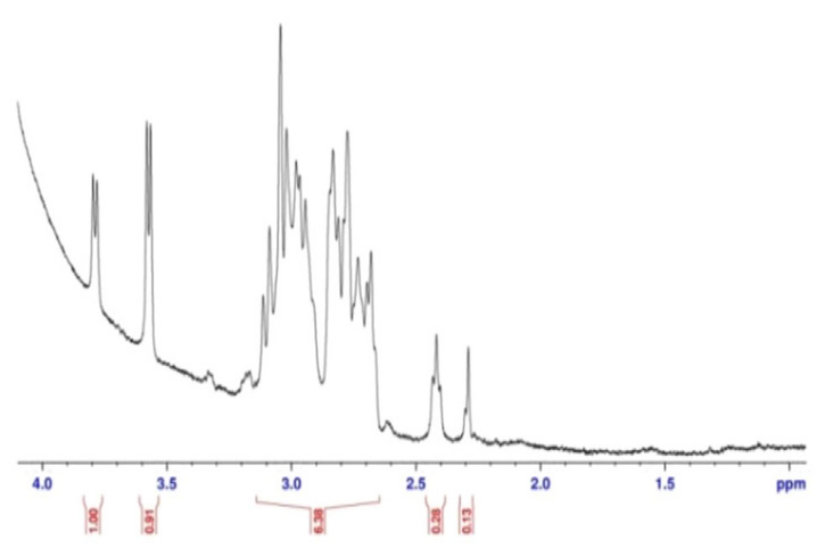

Fig. 1 Graph of NMR illustrating ppm

Table 1 Results of NMR

\begin{tabular}{|c|c|c|c|}
\hline \multicolumn{2}{|c|}{ PEAKS [ppm] } & \multirow{2}{*}{$\begin{array}{l}\text { Chemical compound } \\
\text { (functional group) }\end{array}$} & \multirow{2}{*}{$\begin{array}{l}\text { Chemical shift } \\
(\delta)\end{array}$} \\
\hline $\begin{array}{l}\text { Staring } \\
\text { point }\end{array}$ & $\begin{array}{l}\text { End } \\
\text { point }\end{array}$ & & \\
\hline 2.25 & 2.31 & $\mathrm{R}-\mathrm{NH}_{2}$ & 0.13 \\
\hline 2.37 & 2.45 & $\mathrm{R}-\mathrm{CH}-\mathrm{OH}$ & 0.28 \\
\hline 2.65 & 3.15 & $\mathrm{R}-\mathrm{CH}-\mathrm{O}$ & 6.38 \\
\hline 3.55 & 3.62 & $\mathrm{R}-\mathrm{CH}-\mathrm{NR}_{2}$ & 0.91 \\
\hline 3.75 & 3.85 & $\mathrm{R}-\mathrm{CH}-\mathrm{NR}_{2}$ & 1.00 \\
\hline
\end{tabular}


Fig. 2 Graph of UV plotted between absorption and wavelength $(\mathrm{nm})$

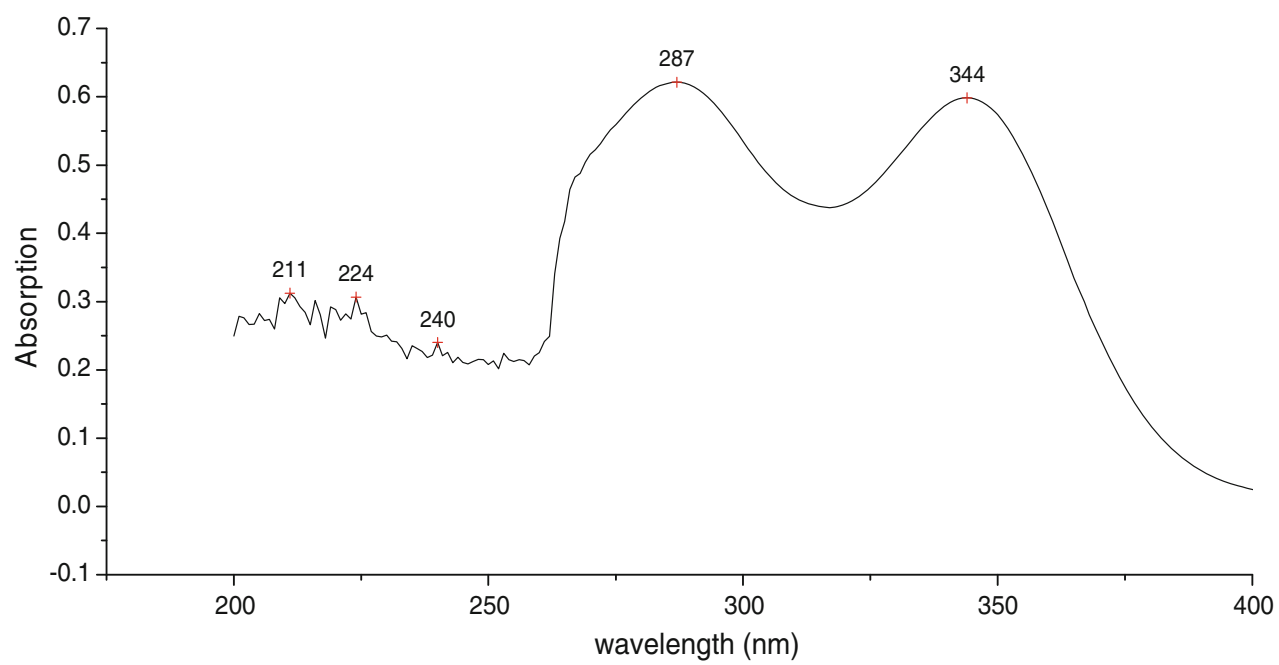

Table 2 Results of UV

\begin{tabular}{lll}
\hline WAVELENGTH $(\mathrm{nm})$ & Absorption & Compounds \\
\hline $\mathbf{2 1 1}$ & 0.3 & Amides \\
$\mathbf{2 2 4}$ & 0.3 & $\left(\mathrm{CH}_{3}\right)_{2} \mathrm{~N}$ \\
$\mathbf{2 8 7}$ & 0.6 & ACETONE \\
$\mathbf{3 4 4}$ & 0.6 & NITRO \\
\hline
\end{tabular}

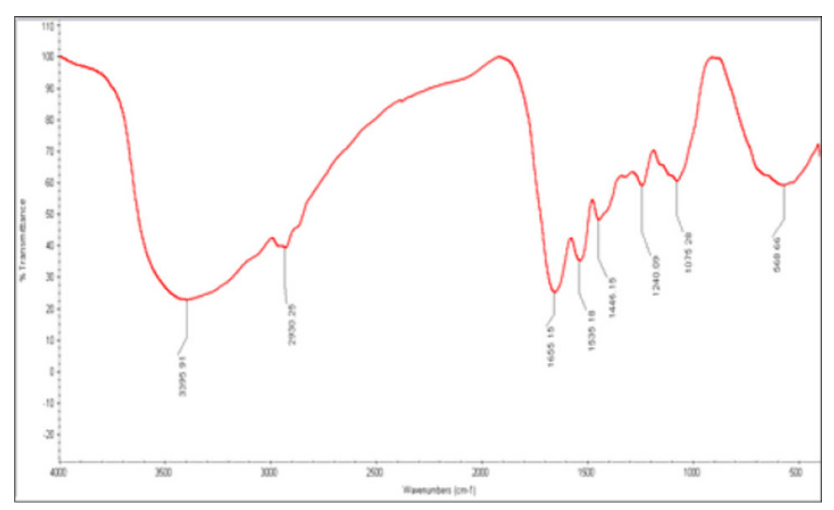

Fig. 3 Graph of IR plotted between \% transmission and wave number

Table 3 Results of IR

\begin{tabular}{lll}
\hline Frequency, $\mathrm{Cm}^{-1}$ & Bonds & Functional group \\
\hline $\mathbf{1 , 0 7 5 . 2 8}$ & C-N stretch & Aliphatic amines \\
$\mathbf{1 , 2 4 0 . 0 9}$ & C-N stretch & Aliphatic amines \\
$\mathbf{1 , 4 4 6 . 1 5}$ & C-C Stretch (in ring) & Aromatic \\
$\mathbf{1 , 5 3 5 . 1 8}$ & N-O asymmetrical & Nitro compound \\
$\mathbf{1 , 6 5 5 . 5 5}$ & $-\mathrm{C}=$ C- stretch & Alkene \\
$\mathbf{2 , 9 3 0 . 2 5}$ & Carboxylic acid & $-\mathrm{COOH}$ \\
$\mathbf{3 , 3 9 5 . 9 1}$ & N-H stretch & $1^{\circ}-2^{\circ}$ Amines, amides \\
\hline
\end{tabular}

Composition: C (49.3\%), H (9.65 \%), N (19.16 \%), and O $(21.89 \%)$

Isotope composition: $\mathrm{C}(49.3 \%), \mathrm{H}(9.65 \%), \mathrm{N}$ (19.16\%), O (21.89\%)

Mass: 146.1876

Exact mass: 146.105527702

Step II: characterization of CNTs after decomposition and purification

Purification is carried out using TEM and XRD. The fictionalizations are studied using FTIR.

\section{TEM result}

TEM images of CNTs are shown in Fig. 4. In TEM images CNTs are clearly visible (Pawlyta et al. 2012). The diffraction pattern of electron bombarded on the sample is given in Fig. 5. It shows the rings of different magnitude which validate the "POLY-CRYSTALLINE" structures of CNTs (Awasthi et al. 2011).

\section{$X R D$ result}

XRD graph of CNTs is shown in Fig. 6. The graph shows that the intensity of the peaks is in the range of 25.0-25.9. The results were found to be almost similar to the results reported by for multi-walled CNTs prepared by Bhattacharji et al. (2011) by pyrolysis of turpentine oil $(2 \theta=25.6)$ and with Ioan Stalin et al. (2007), who prepared CNTs by catalytic pyrolysis of phenol formaldehyde resin $(2 \theta=26.2)$.

This confirms the formation of multi-walled CNTs which proves the existence of CNTs in the sample. 


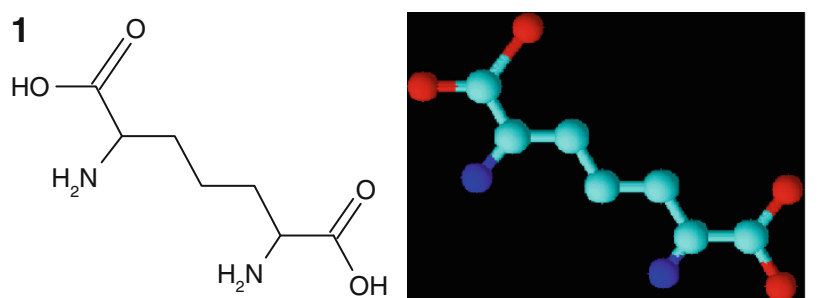

2

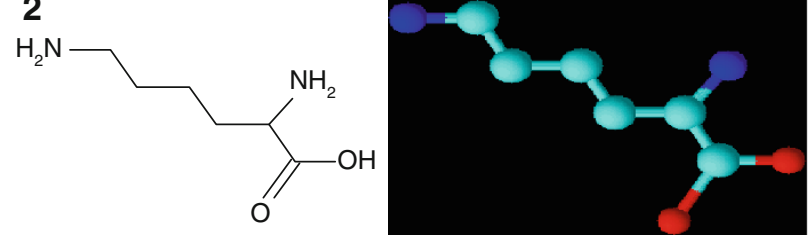

Fig. 41 Deduced chemical structure. 2 Chemical structure of Lysine

\section{FTIR results}

The Fourier transform infra-red test of the CNTs synthesized is carried out. The FTIR spectra are illustrated in
Fig. 7. The graph tells about the various functional groups present in the CNTs formed which is described in the Table 4

Study of properties of CNTs Magnetic and thermal properties of CNTs were studied using VSM, TGA-DTA.

Study of magnetic properties Magnetic properties of CNTs are studied using VSM.

\section{VSM results}

The magnetic properties of CNTs can be deduced using VSM. The sample of CNTs prepared by us is analyzed using VSM and a graph is plotted between magnetic field and magnetic moment. A blank/reference graph is also prepared taking the same value of magnetic field for ready reference. It is observed that the magnetic moment of the sample is more than the magnetic moment of the blank. This shows the paramagnetic behavior of the CNTs
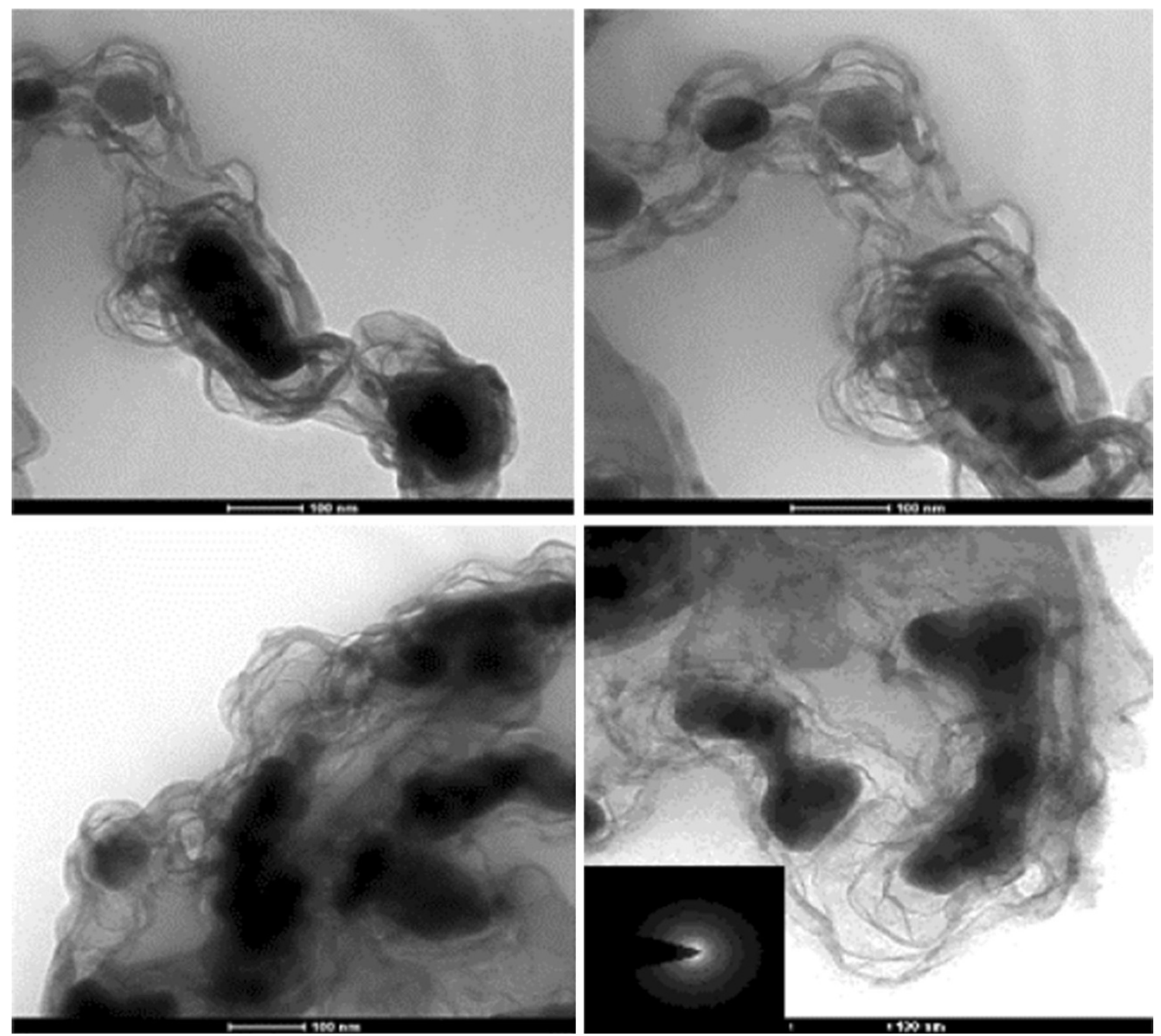

Fig. 5 Results of TEM at magnification of $100 \mathrm{~nm}$ and diffraction pattern 
Fig. 6 Graph of XRD plotted between lin (counts) and 2theta scale [wider range]. Graph of XRD plotted between lin (counts) and 2theta scale [CNTs range]
Fig. 7 Graph of FTIR plotted between $\%$ transmission and wave number
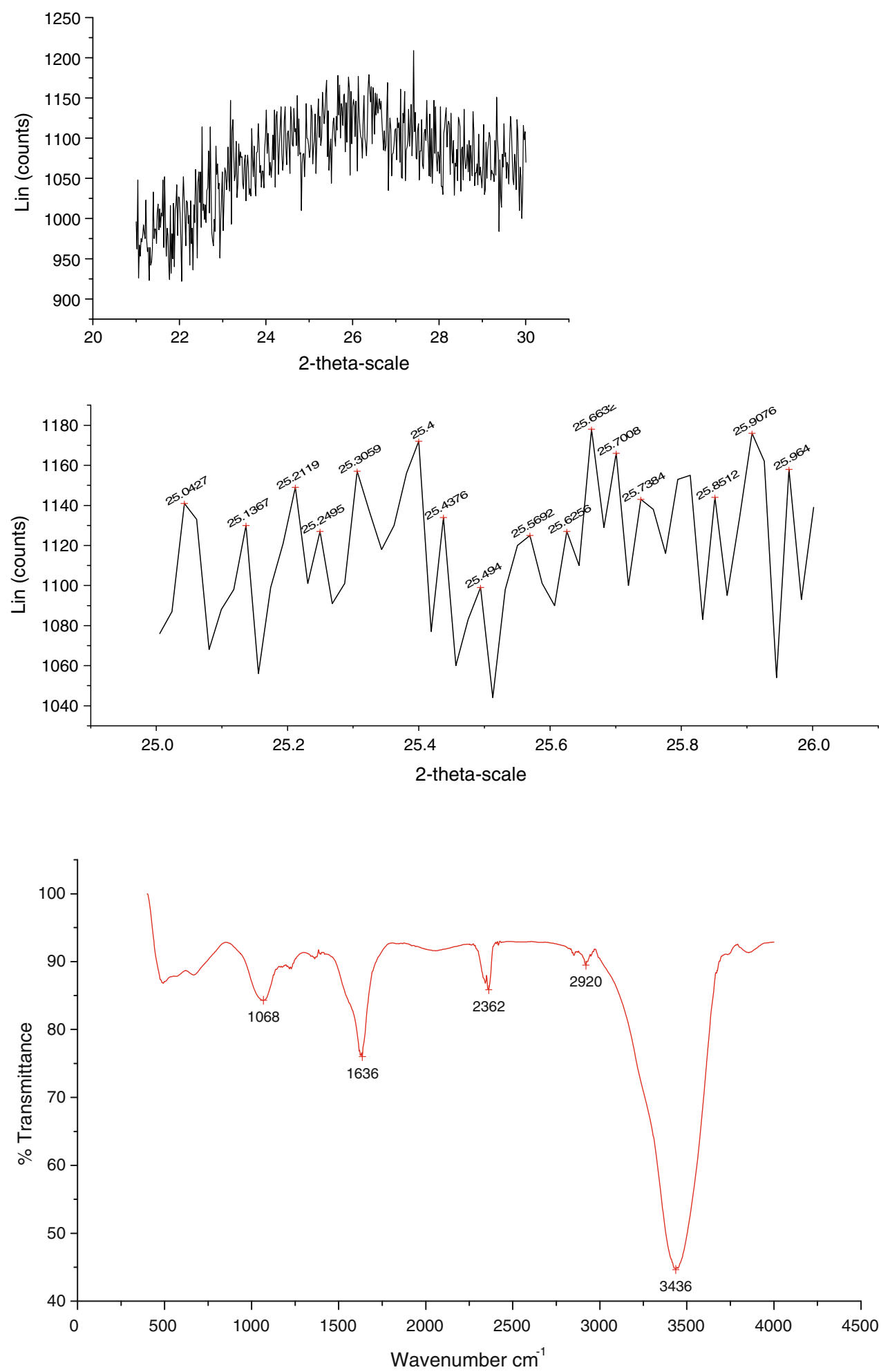

produced (Tiwari et al. 2012). CNTs are usually diamagnetic in nature in our sample all free cobalt ions are removed during process of purification. The magnetic nature can be because of cobalt ions embedded inside the tube. LI Wei-Xue et al. (2007) studied the magnetic properties of multi-walled carbon nanotube encapsulated
Fe/Co particles. Their graph shows resemblance with the graph of my sample. In both the graphs CNTs are paramagnetic in nature. Graphs show an increase in magnetic moment with increase in magnetic field strength. K. Atre et al. (2008) of Nanomaterial and nano research laboratory, USA synthesized vertically aligned carbon nanotubes. 
Table 4 Results of FTIR

\begin{tabular}{lll}
\hline Frequency $\mathrm{cm}^{-1}$ & Bonds & Functional group \\
\hline $\mathbf{1 , 0 6 8}$ & C-N stretch & Aliphatic amine \\
$\mathbf{1 , 6 3 6}$ & N-H bend & $\mathrm{I}^{\circ}$ amine \\
$\mathbf{2 , 9 2 0}$ & C-H stretch & Carboxylic acid \\
$\mathbf{3 , 4 3 6}$ & O-H stretch & Phenol \\
\hline
\end{tabular}

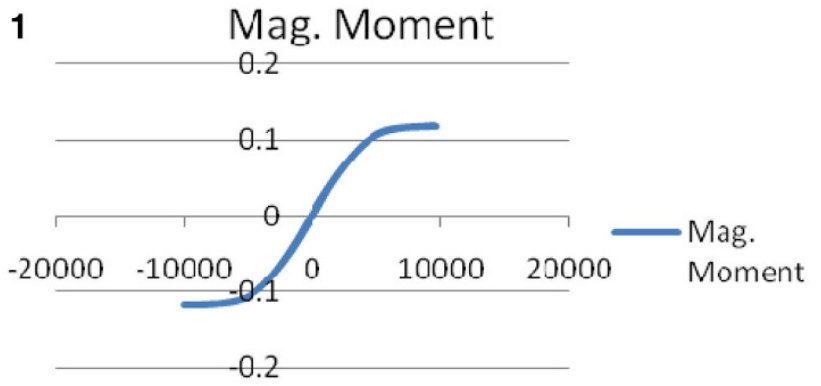

2

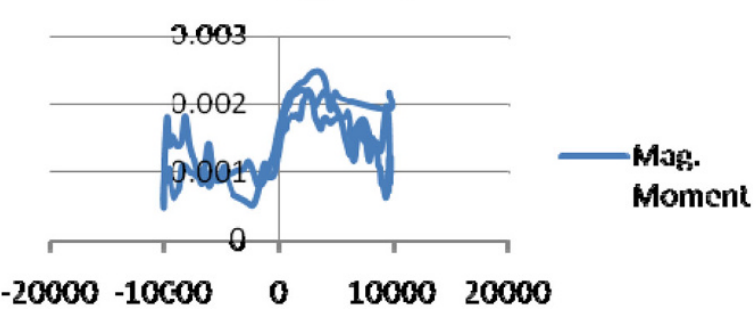

Fig. 81 VSM graph for sample. 2 VSM graph for reference/blank

They also studied magnetic properties using VSM. Their VSM graph also showed similar findings and resembled with the graph of our sample (Fig. 8).
Study of thermal properties The thermal properties of CNTs formed are studied using TGA and DTA.

\section{DTA-TGA result}

TGA-DTA analysis of CNTs was carried out in the atmosphere of Nitrogen.

The following graph shows the relation between the temperature and weight $\%$ loss and temperature. It also shows high thermal conductivity and thermal stability of CNTs formed. Chang et al. (2004) studied thermal properties of multiwall carbon nanotubes dispersed in water and associated with biological effect using TGA and DTA. Sumio Iijima et al. (2007) also studied the thermal properties of carbon nanotubes ultrasonicated in monochloro benzene (Fig. 9).

The results of all the tests show that the sample contains multi-walled carbon nanotubes that are formed. TEM analysis results show that the nanotubes so formed were of $100 \mathrm{~nm}$ size and structurally polycrystalline. FTIR results show that CNTs are functionalized. The properties of the compound formed were also studied using VSM, TGADTA. VSM results shows that the CNTs formed are paramagnetic in nature. The paramagnetic nature can be because of nickel ions embedded inside the tube.

TGA-DTA result shows that as with the increase in temperature the \% weight of the sample decreases. The results of DTA-TGA show that CNTs have high thermal conductivity and their thermal stability is high.

The methodology used for preparing the CNTs was chemical and biological and shows successful decomposition of protein and metal complex into CNTs.
Fig. 9 Graph of TGA-DTA plotted between temperature, weight $\%$ and differential temperature

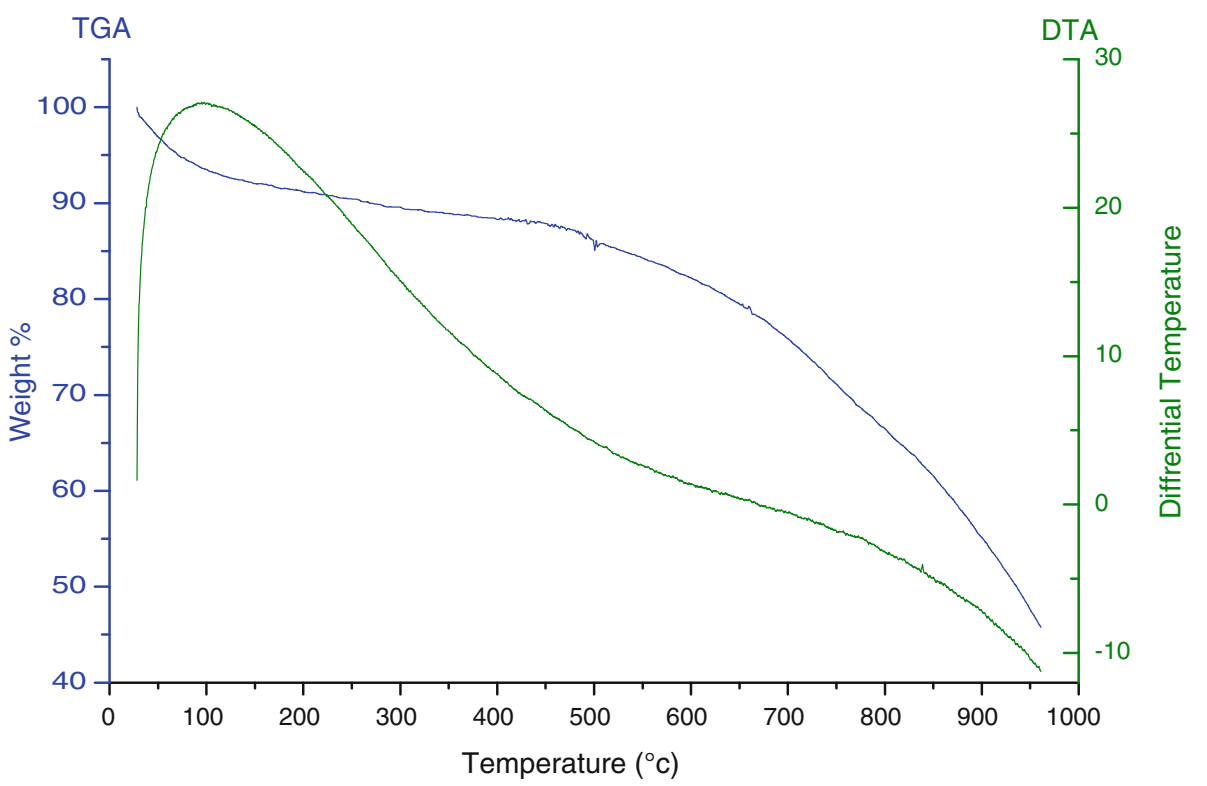




\section{Conclusion}

The sample formed was analyzed using a number of characterization techniques such as TEM, XRD, FTIR, IR, $\mathrm{UV}$, and NMR.

Open Access This article is distributed under the terms of the Creative Commons Attribution License which permits any use, distribution, and reproduction in any medium, provided the original author(s) and the source are credited.

\section{References}

Aatre K et al (2008) Synthesis of vertically aligned carbon nanotube and magnetic CNTs for cellular growth and detection. In: Proc of SPIC 6931

Alberto Bianco et al (2005) Application of carbon nanotube in drug delivery. Elsevier 9(6):674-679

Awasthi Kalpana et al (2011) Synthesis of nano-carbon (nanotubes, nanofibres, graphene) materials. Indian Acad Sci 34(4):607-614

Bhattacharji CR, Nath A et al (2011) Synthesis and characterization of carbon nanotubes using a national precursor turpentine oil. Sci J UBU 2:36-42
Dresslhaw MS et al (2008) Carbon nanotube synthesis, structure, properties and application. Spinger, Heidelberg

Elhissi MA et al (2012) Carbon nanotube in cancer therapy and drug delivery. J Drug Deliv 2012, Article ID 837327

Iijima Sumio et al (2004) Thermo gravimetric analysis of single wall carbon nanotubes ultrasonicated in mono chloro benzene. Chem Phy Lett 364:420-426

Pawlyta M, Lukowiec D, Dobrzanska-Danikiewicz AD (2012) Characterization of carbon nanotubes decorated with platinum nanoparticles. J Achiev Mater Manuf Eng 53(2)

Stalin I et al (2007) Synthesis and characterization of carbon nanotubes by catalytic pyrolysis of phenol formal resigns. Phys E 37:44-48

Tiwari, IP Tripathi, Sanjay Saxena, Synthesis (2011) characterisation and study of properties of CNTs prepared by egg protein and metal salt. Indian J Appl Res 3(2)

Tiwari B, Tripathi IP, Saxena S (2012) Synthesis of carbon nanotubes using spinach, characterization and study of magnetic properties. J Indian Chem Soc 89:1143-1148

Wei-xue LI, Yuan HAO, Yong-fu CUI, Jian-feng DAI, Ti-jun CHEN, Qing WANG, Zhong-li WU, Yang LI (2007) Magnetic properties of multi-walled carbon nanotubes encapsulated $\mathrm{Fe} / \mathrm{Co}$ particles. J Trans Non Ferrous Metal Soc China 17:696-699 